\title{
Intracellular Sites of Synthesis of Encephalomyocarditis Virus Components in Krebs-2 Ascites Tumour Cells
}

\author{
By A. J. D. BELLETT AND A. T. H. BURNESS \\ Virus Research Unit, Medical Research Council Laboratories, Carshalton, \\ Surrey, England
}

(Received 23 May 1962)

SUMMARY

Ascites tumour cells were homogenized and fractionated at various times after infection with encephalomyocarditis virus in vitro. Infective ribonucleic acid (RNA) could be obtained from the nuclear fraction soon after infection and the amount of infective RNA recovered from this fraction increased until a maximum was reached at about $4 \frac{1}{2} \mathrm{hr}$. From $4 \frac{1}{2} \mathrm{hr}$. onwards the amount of infective RNA associated with the nuclear fraction fell while that from the mitochondrial fraction increased, reaching a maximum at about $5 \frac{1}{2} \mathrm{hr}$. The amount of haemagglutinin and plaque-forming virus began to increase at about $4 \frac{1}{2} \mathrm{hr}$. and continued to rise until $8 \mathrm{hr}$. Most of this virus activity was found in the mitochondrial fraction, although from $6 \mathrm{hr}$. onwards an increasing amount was found in the microsomal fraction.

\section{INTRODUCTION}

Murine encephalomyocarditis (EMC) virus is a small ribonucleic acid (RNA) virus which can be grown under one-step conditions in agitated suspensions of ascites carcinoma cells (Sanders, Huppert \& Hoskins, 1958). After infection there is an

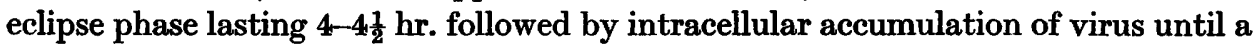
maximum is reached about $8 \mathrm{hr}$. after infection. From 8 to $12 \mathrm{hr}$. virus is released into the medium; at the same time the cells die.

Huppert \& Sanders (1958) obtained infective RNA preparations by cold $\left(4^{\circ}\right)$ phenol extraction of infected cells, but similar preparations from partially purified EMC virus were not infective. This led the authors to postulate that the source of infective RNA in infected cells was not the virus, but an RNA component which might be a virus precursor. Bellett et al. (1962) have shown that infective RNA can be obtained from virus by using the improved cold phenol extraction described by Sanders (1960), and that the result obtained by Huppert \& Sanders (1958) may have been due to ribonuclease in their preparations. The synthesis and subsequent fate of virus precursor RNA have, therefore, been followed by studying changes in the amount of infective RNA which occur without corresponding changes in virus titre. Such studies of ascites cells infected by EMC virus confirm that the synthesis of infective RNA begins 1-2 hr. before virus formation begins, and is complete $3 \mathrm{hr}$. before virus reaches its maximum titre (Sanders, 1960). Martin \& Work (1962) showed that $60 \%$ of the RNA destined to be incorporated into virus particles has been synthesized before virus protein synthesis begins $4 \mathrm{hr}$. after infection. Cells inhibited by the addition of euflavine 4-5 hr. after infection produce the normal amount of infective RNA, but no haemagglutinin or infective virus (Sanders, 1960). 
As a working hypothesis, the multiplication of EMC virus in this system has therefore been divided into the following stages given in chronological order:

(1) synthesis of a precursor, consisting of or containing infective RNA,

(2) synthesis of haemagglutinin,

(3) assembly of RNA and protein into plaque-forming virus particles.

Experiments reported here were designed to determine in which part of the infected cell each stage occurs.

\section{METHODS}

Cell cultures and virus growth. Krebs-2 ascites cells at a concentration of $10^{8} / \mathrm{ml}$. in phosphate buffered saline (PBS) were infected with 3 plaque forming units (pfu) of EMC virus (K-2 strain)/cell and left at $4^{\circ}$ for one or more hours. Storage at $4^{\circ}$ for up to $16 \mathrm{hr}$. had no effect on subsequent virus yield. These infected cells were then diluted rapidly to $10^{7} / \mathrm{ml}$. in Earle's saline at $37^{\circ}$ and maintained in suspensions; one-step growth of virus with maximum possible synchrony of multiplication occurred under these conditions. Thus, times after infection referred to were times after transfer to $37^{\circ}$. After virus growth the cultures were chilled rapidly and kept at $0^{\circ}$ during all subsequent procedures. Cells were harvested, washed once in PBS free of calcium and magnesium and resuspended to a concentration of $10^{8} / \mathrm{ml}$. A sample was removed as a control; the remainder was lysed and separated into sub-cellular fractions.

Lysis and fractionation of cells. Cells were lysed by double osmotic shock followed by homogenization (Martin, Malec, Coote \& Work, 1961). The lysate was centrifuged at $500 \mathrm{~g}$ (max.) for $5 \mathrm{~min}$. at $0^{\circ}$, the deposited nuclear fraction washed once in about 5 vol. of a solution containing $0.25 \mathrm{M}$-sucrose and $0 \cdot 1 \mathrm{M}-\mathrm{KCl}$, and the washings added to the supernatant fluid. The crude nuclei were further purified by homogenization at c. $1000 \mathrm{rev} . / \mathrm{min}$. for $15 \mathrm{sec}$. in $10 \mathrm{vol}$. of $2 \mathrm{M}$-sucrose, followed by centrifugation at $40,000 \mathrm{~g}$ for $30 \mathrm{~min}$. Nuclei were deposited while whole cells and nuclei with attached cytoplasm formed a band at the top of the tube (Busch, Starbuck \& Davis, 1959). The purified nuclei were washed in the sucrose $\mathrm{KCl}$ solution and resuspended in this solution to give about $5 \times 10^{7}$ nuclei $/ \mathrm{ml}$.

The cell homogenate after removal of nuclei at $500 \mathrm{~g}$ was centrifuged at $9,000 \mathrm{~g}$ for $15 \mathrm{~min}$. then at $144,000 \mathrm{~g}$ for $45 \mathrm{~min}$. to deposit the mitochondrial and microsomal fractions, respectively, leaving the supernatant fiuid as cell sap. The mitochondrial and microsomal fractions were resuspended in the same volume of $0.25 \mathrm{M}$-sucrose + $0 \cdot 1 \mathrm{M}-\mathrm{KCl}$ as that used for the nuclei. Samples were removed for deoxyribonucleic acid (DNA) and succinic dehydrogenase determinations, and the remainder was stored at $-20^{\circ}$ until used for RNA extraction and haemagglutinin and plaque titrations.

Purity of the fractions. We have followed the common practice of calling the $500 \mathrm{~g}$, $9000 \mathrm{~g}$ and $144,000 \mathrm{~g}$ deposits the nuclear, mitochondrial and microsomal fractions respectively, to indicate the main constituents of the fractions. The material not sedimented at $144,000 \mathrm{~g}$ we have called cell sap. Each of these fractions probably contains minor components, and the main constituent of a fraction is not necessarily involved in synthesis of virus material.

Since our results were affected by contamination of one fraction by another, it was necessary to estimate the extent of such contamination. We attempted to do this by cytological and biochemical investigations of the fractions. Haemocytometer counts 
of the crude lysates after staining for $5 \mathrm{~min}$. in 10 vol. of $0.2 \%(\mathrm{w} / \mathrm{v})$ nigrosin in $0.3 \mathrm{M}-\mathrm{KCl}$ showed that they usually contained more than $95 \%$ nuclei and less than $5 \%$ whole cells. Similar counts of the nuclear fraction after purification showed on average $86 \%$ nuclei without cytoplasmic attachments, $9 \%$ nuclei with cytoplasmic attachments, $5 \%$ free cytoplasmic fragments and less than $1 \%$ whole cells based on counts of about 100 nuclei. These results were confirmed by observing unstained material with the phase-contrast microscope. About 0.7\% of the nuclei in the crude lysate was deposited with the mitochondrial fraction as shown by staining with two volumes of $0.2 \%(\mathrm{w} / \mathrm{v})$ nigrosin.

The contamination of other fractions by mitochondria can be estimated by their content of succinic dehydrogenase, a known mitochondrial enzyme, determined by the method of Aldridge \& Johnson (1959). The nuclear fraction usually contained about $10 \%$ and microsomes and cell sap up to $2.0 \%$ of mitochondria or unbroken cells. Contamination in excess of these figures is mentioned in the text. Similarly, DNA was used as a measure of nuclear contamination of the cytoplasmic fractions. DNA was extracted by the Schneider technique as modified by Ogur \& Rosen (1950) and determined by the method of Burton (1956). Over $96 \%$ of the DNA was found in the nuclear fraction, between $0 \cdot 3-2 \cdot 8 \%$ in the mitochondrial fraction, $0 \cdot 4-1 \cdot 4 \%$ in the microsomal fraction, and $0 \cdot 2-1 \cdot 1 \%$ in the cell sap. Nuclear contamination of cytoplasmic fractions was, therefore, not significant.

Infectious $R N A$. This was prepared by phenol extraction at $4^{\circ}$ (Gierer \& Schramm, 1956; Sanders, 1960) with $0 \cdot 25 \mathrm{M}$-sucrose $+0 \cdot 1 \mathrm{M}-\mathrm{KCl}$ as the suspending medium during extraction. The concentration of RNA was estimated by optical density measurements at $260 \mathrm{~m} \mu$. All samples had spectra typical of RNA. Infectivity of RNA preparations was estimated by mixing dilutions in PBS with an equal volume of Krebs-2 ascites cells $\left(10^{8} / \mathrm{ml}\right.$.) in PBS. Five mice per dilution were inoculated intraperitoneally with $\mathbf{0 . 2} \mathrm{ml}$. of mixture after it had stood at room temperature for $30 \mathrm{~min}$. (Huppert \& Sanders, 1958). LD 50 endpoints were calculated by the method of Reed \& Muench (1938). Results were expressed in terms of infectivity (LD 50/10 ${ }^{8}$

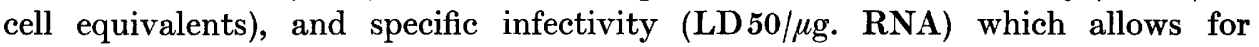
differences in recovery of RNA. A fraction in which infective RNA is concentrated can be identified since its specific infectivity will exceed that of whole cells. Specific infectivity may, however, obscure the importance of a fraction rich in noninfective RNA (e.g. microsomes) so that it is also necessary to consider results in terms of infectivity per $10^{8}$ cell equivalents.

Haemagglutinin tests were performed in MRC pattern plastic trays with sheep red blood cells $(0 \cdot 1 \%, \mathrm{v} / \mathrm{v})$. The diluent was one part glucose solution $(4.5 \%, \mathrm{w} / \mathrm{v})+$ 1 part PBS with $0.05 \%(\mathrm{w} / \mathrm{v})$ gelatin added.

Virus titrations were by a plaque technique using Krebs-2 ascites cells in agar suspension (Sanders et al. 1958). Plates were incubated in a sealed vessel containing $\mathrm{CO}_{2}$ buffer (Bellett, 1960).

\section{RESULTS}

Absence of non-specific adsorption by cell fractions. One possible disadvantage of cell fractionation in the study of the intracellular location of virus materials is nonspecific adsorption of these materials by cell particles after homogenization of the cells (Stickl, quoted by Breitenfeld \& Schäfer, 1957). Two experimental facts suggest 
that non-specific adsorption is not significant in the EMC-ascites cell system. First, the distribution of virus materials between cell fractions varies with time after infection. Secondly, virus added directly to a cell homogenate sedimented with the microsomes as expected and showed no evidence of non-specific adsorption (Table 1).

Infective $R N A$ in the nuclear fraction immediately after infection. When cells were fractionated after $30 \mathrm{~min}$. contact with virus at $4^{\circ}$, infective RNA was recovered from the nuclear fraction while RNA from other fractions was non-infective (Table 2). The specific infectivity (LD 50/ $\mu \mathrm{g}$.) of nuclear RNA was greater than that of whole cell RNA since the latter was diluted with non-infective RNA from other fractions. After a further hr. at $4^{\circ}$, the infectivity of RNA from the nuclear fraction did not increase, but a small amount of infectivity was detected in the mitochondrial fraction, not all of which could be accounted for by nuclear contamination. The specific infectivity of RNA from the mitochondrial fraction did not exceed that from whole cells.

Table 1. The distribution of virus added to an homogenate of uninfected cells

\begin{tabular}{|c|c|c|}
\hline \multirow[b]{2}{*}{ Cell fraction } & \multicolumn{2}{|c|}{ Virus } \\
\hline & $\begin{array}{c}\text { Haemagglutinating } \\
\text { units total }\end{array}$ & $\begin{array}{l}\text { Plaque forming units } \\
\text { total }\left(\times 10^{-5}\right)\end{array}$ \\
\hline Nuclei & 25 & 20 \\
\hline Mitochondria & 200 & 200 \\
\hline Microsomes & 800 & 1950 \\
\hline Sap & $<175$ & 250 \\
\hline
\end{tabular}

Virus (2000 haemagglutinating units, $3 \times 10^{8}$ plaque forming units) was added to an homogenate of Krebs-2 ascites cells which was then centrifuged to give subcellular fractions.

Table 2. Infective RNA in the nuclei of cells infected at $4^{\circ}$

$\begin{array}{lccccc}\text { Cell fraction } & \overbrace{\text { Infectivity }} & \begin{array}{c}\text { Specific } \\ \text { infectivity }\end{array} & \overbrace{\text { Infectivity }}^{90 ~ m i n . ~} & \begin{array}{c}\text { Specific } \\ \text { infectivity }\end{array} \\ \text { Whole cells } & 32 & 0 \cdot 026 & 68 \cdot 0 & 0.072 \\ \text { Nuclei } & 69 & 0 \cdot 220 & 24 \cdot 6 & 0.160 \\ \text { Mitochondria } & 0 & 0 & 1 \cdot 0 & 0.015 \\ \text { Microsomes } & 0 & 0 & 0 & 0 \\ \text { Cell sap } & 0 & 0 & 0 & 0\end{array}$

Cells were infected with 3 p.f.u. of virus per cell and kept at $4^{\circ}$ for the stated times. The cells were then lysed and fractionated. RNA was extracted from the fractions, its concentration was estimated by optical density measurements at $260 \mathrm{~m} \mu$ and its infectivity for mice was determined. Infectivity, LD50/10 $0^{8}$ cell equivalents; specific infectivity, LD 50/ $\mu$ g. RNA.

Synthesis of infective RNA in the nuclear fraction of infected cells during the eclipse phase. Synthesis of infective RNA apparently occurred in the nuclear fraction when infected cells were transferred from $4^{\circ}$ to $37^{\circ}$. The infectivity of RNA from the nuclear fraction increased rapidly from about $3 \mathrm{hr}$. after transfer to $37^{\circ}$ (Fig. 1), reaching a maximum at about $4 \frac{1}{2} \mathrm{hr}$. and exceeded the specific infectivity of whole cell RNA during this period (Fig. 2). The infectivity of RNA from the mitochondrial fraction increased slightly during the eclipse phase but did not exceed the specific infectivity of whole cell RNA. Microsomal and cell sap RNA showed little infectivity throughout the eclipse phase. 
Association of infective RNA with the mitochondrial fraction after the eclipse phase. There was a loss of infective RNA from the nuclear fraction between $4 \frac{1}{2}$ and $8 \mathrm{hr}$. after infection (Figs. 1 and 2). This was accompanied by an increase in both the infectivity and specific infectivity of RNA extracted from the mitochondrial fraction from $4 \frac{1}{2}$ to $5 \frac{1}{2} \mathrm{hr}$. No comparable increase occurred in the infectivity of microsomal or cell sap RNA. The amount of infective RNA recovered from all fractions

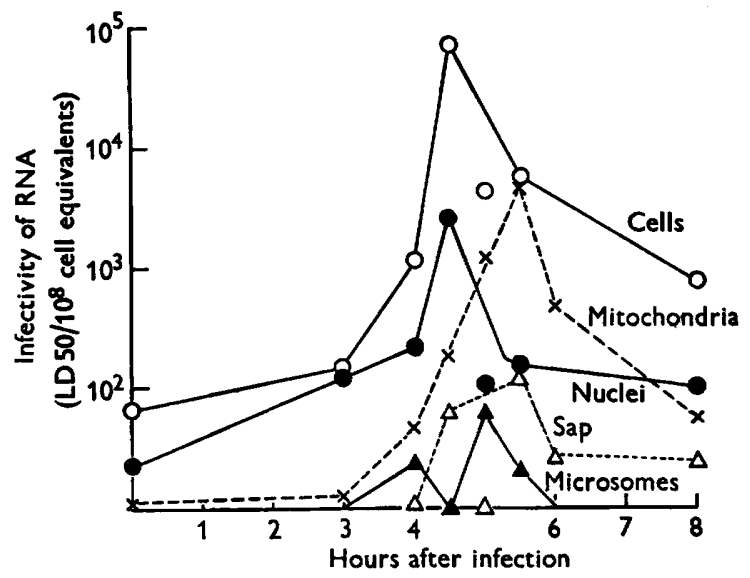

Fig. 1. Infectivity (LD 50/10 $/ 10^{8}$ cell equivalents) of RNA extracted from fractions of infected cells during virus growth. Hours after infection refers to time of incubation at $37^{\circ}$. $\bigcirc-O$, cells; -0 , nuclei; $x---x$, mitochondria; $\Delta-\Delta$, microsomes; $\triangle \cdots .-\Delta$, sap.

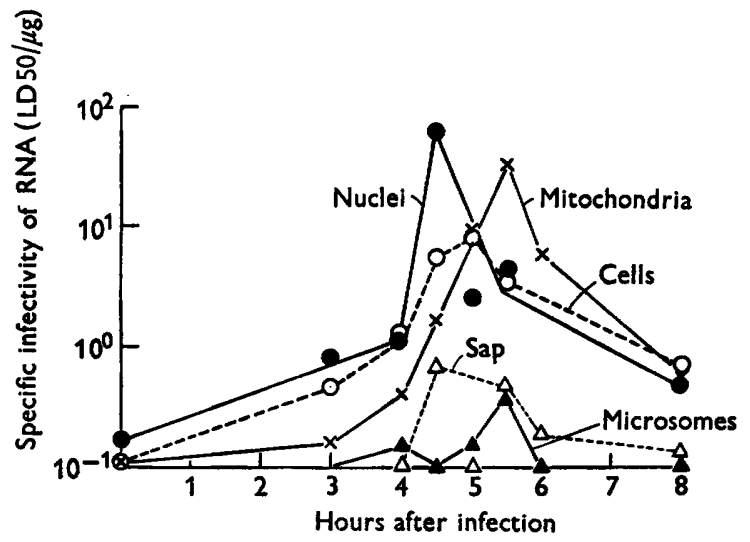

Fig. 2. Specific infectivity (LD50/ $\mu \mathrm{g}$.) of RNA extracted from infected cells during virus growth. $O_{-}-0$, cells; -0 , nuclei; $x-\times$, mitochondria; $\Delta-\Delta$, microsomes; $\triangle \cdots-\triangle$, sap.

decreased from $5 \frac{1}{2}$ to $8 \mathrm{hr}$. This loss was also reported by Sanders (1960) who suggested it was due to incorporation of RNA into virus particles, whence it could not be extracted in an infective form with cold phenol. While we can now obtain infective RNA from virus by the technique used in this paper, it still seems that it may be more difficult to obtain it from virus within cells $5 \frac{1}{2}$ to $8 \mathrm{hr}$. after infection 
than from precursor RNA or extracellular virus. From $10^{9} \mathrm{pfu}$ of extracellular virus we usually obtained about $10^{5}$ LD50 of infective RNA. However, from $10^{9} \mathrm{pfu}$ of virus within $8 \mathrm{hr}$. infected cells we obtained only $3 \times 10^{8}$ LD 50 of RNA. The reduced recovery of RNA from all fractions after $5 \frac{1}{2} \mathrm{hr}$. may, therefore, be due to assembly of the RNA component into virus particles which, within cells, are apparently more resistant to phenol extraction.

Association of haemagglutinin with mitochondria after the eclipse phase. Haemagglutinin increased rapidly from about $4 \frac{1}{2}-8 \mathrm{hr}$.; most of the haemagglutinin was found in

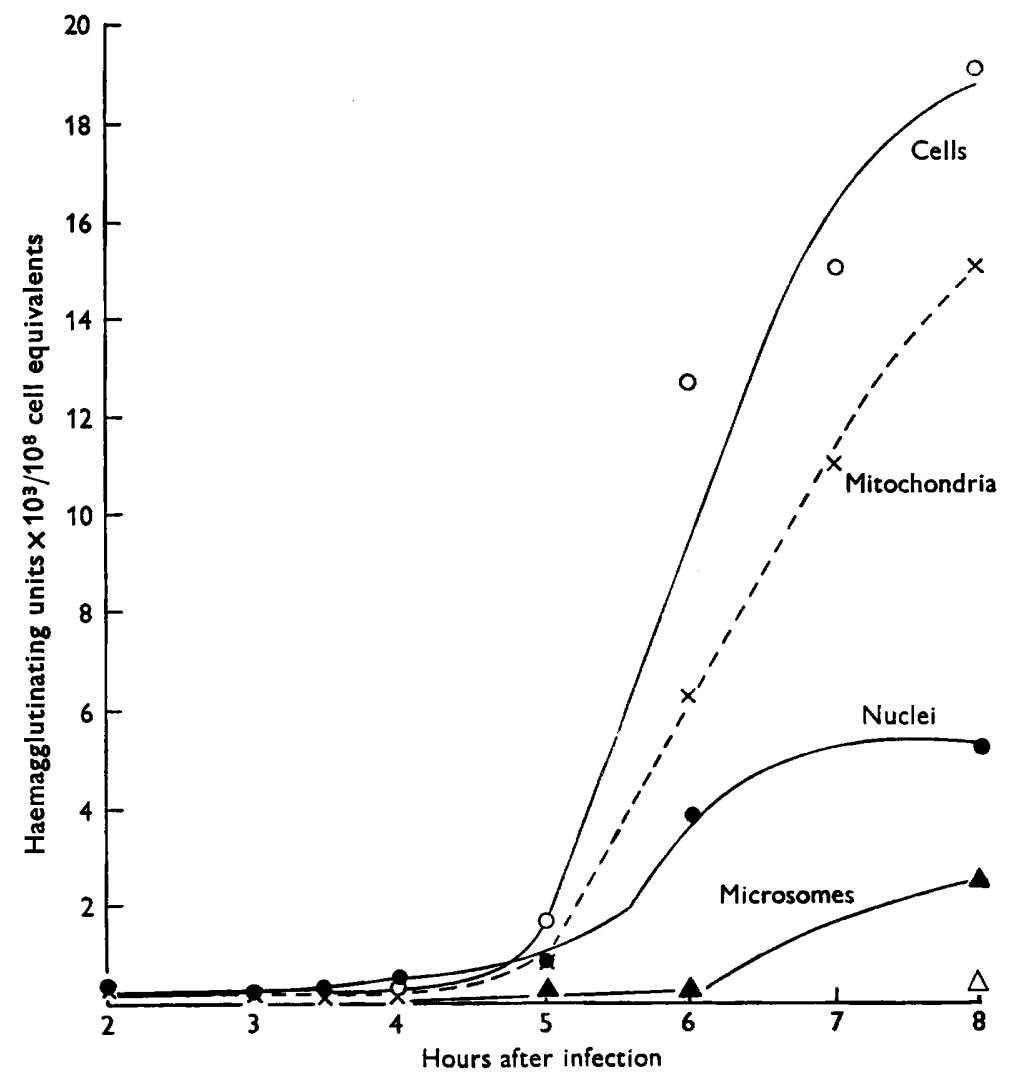

Fig. 3. Haemagglutinin in fractions of infected cells during virus growth. $\bigcirc-\bigcirc$, cells; $\longrightarrow$, nuclei; $x-x$, mitochondria; $\Delta---\Delta$, microsomes; $\Delta$, sap.

the mitochondrial fraction, which showed the greatest increase in titre during this period (Fig. 3). The nuclear fraction also contained haemagglutinin which increased in titre during the same period but neither the amount of haemagglutinin nor its increase was as great as that found in the mitochondrial fraction. Further, some of this haemagglutinin may have been due to cytoplasmic contamination, since $19 \%$ of the succinic dehydrogenase activity was found in the nuclear fraction at $8 \mathrm{hr}$. The microsomal fraction showed an increase in haemagglutinin from 6 to $8 \mathrm{hr}$. after infection, although the total amount was still low; this increase was probably not due to cytoplasmic contamination $(<1 \%)$. This suggests that some haemagglutinin 
had been incorporated into virus particles which were then liberated from the mitochondrial fraction and so were deposited with the microsomes which have similar sedimentation properties (Table 1).

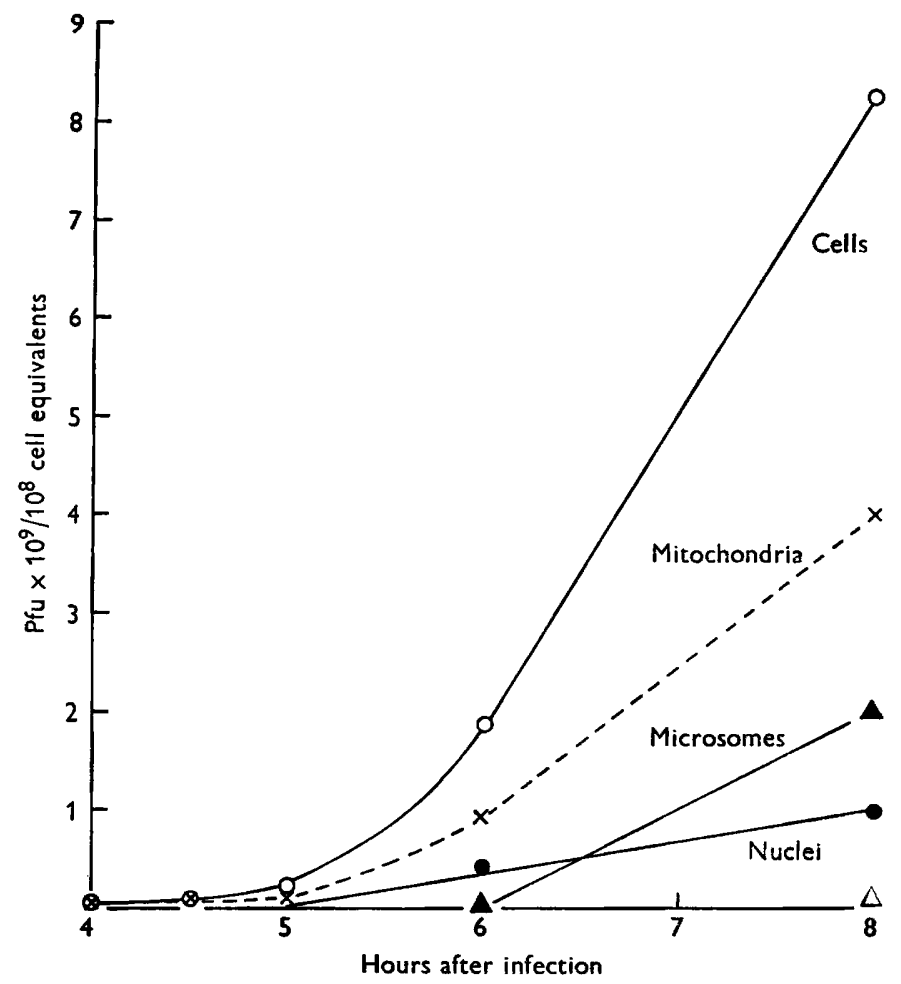

Fig. 4. Plaque-forming virus in fractions of infected cells during virus growth. $\mathrm{O}-\mathrm{O}$, cells;

Association of virus progeny with the mitochondrial fraction. Infective (plaqueforming) virus was detected in the mitochondrial fraction at $4 \frac{1}{2} \mathrm{hr}$. after infection (Fig. 4) and increased rapidly up to $8 \mathrm{hr}$. after infection, representing a substantial proportion of the virus found in the whole cell control. The nuclear fraction also contained virus; this showed little increase in titre and, as suggested in the case of haemagglutinin, may have been due to cytoplasmic contamination at $8 \mathrm{hr}$. Little virus was detectable in the microsomal fraction before $6 \mathrm{hr}$. but, between 6 and $8 \mathrm{hr}$. after infection a marked increase in titre occurred, reaching $30 \%$ of the total virus at $8 \mathrm{hr}$. This increase was greater than the increase in haemagglutinin of the microsomal fraction and provided further evidence that completed virus particles were released from the mitochondrial fraction and were then deposited with the microsomes on centrifugation (Table 1).

\section{DISCUSSION}

The infective RNA obtained from the nuclear fraction after infection of cells at $4^{\circ}$ may be derived from complete virus particles or from some component (which may be RNA) released by them. However, the RNA synthesized during the first $4 \frac{1}{2} \mathrm{hr}$. 
after transfer to $37^{\circ}$ appeared to be in the form of RNA component and not virus, since increase in the amount of infective RNA obtained was not accompanied by a corresponding increase in haemagglutinin or plaque-forming virus. Increase in the infectivity of nuclear RNA between 0 and $4 \frac{1}{2} \mathrm{hr}$. and the subsequent decrease may then be interpreted as synthesis of the RNA component in the nuclei and the transfer of this component to the cytoplasm to initiate the production of haemagglutinin and infective virus. Another interpretation is that the RNA is synthesized elsewhere and concentrated in the nuclear fraction; but this is unlikely since other fractions are virtually free of infective RNA until $4 \mathrm{hr}$. after infection. It has also been suggested (Franklin \& Rosner, 1962) that our results might have been due to contamination of our nuclear fraction by viral RNA of cytoplasmic origin. We attempted to assess this type of contamination in the nuclear fraction by measuring the activity of succinic dehydrogenase, which is a mitochondrial enzyme. The amount of infective RNA recovered from the nuclear fraction could not be correlated with the amount of cytoplasmic contamination in a series of experiments at a given time after infection. Further, in one experiment, although there was no succinic dehydrogenase activity in the nuclear fraction, three times more infective RNA was recovered from this fraction than from all the cytoplasmic fractions put together. In another experiment infective RNA was recovered immediately after infection only from the nuclear fraction, whereas if this RNA resulted from contamination with cytoplasmic material, some infective RNA should also have been obtained from the cytoplasmic fractions.

Some of the infective RNA obtained from the mitochondrial fraction from $5 \mathrm{hr}$. onward may come from virus although the bulk of the RNA must be from the RNA component up to $5 \mathrm{hr}$. since little virus is detectable during this time. It thus appears that the RNA component is transferred from the nuclear fraction to the mitochondrial fraction and only then does synthesis of haemagglutinin and production of complete virus begin.

The synthesis of haemagglutinin and assembly of virus components into plaqueforming particles took place in the cytoplasm and was associated with the mitochondrial fraction. This result was also obtained by Martin \& Work (1961), and can be interpreted in at least four ways:

(1) Virus material free in the cell was non-specifically adsorbed by the mitochondria which are not involved in virus synthesis. The results of an experiment in which virus was added to a homogenate of uninfected cells (Table 1) suggest that this is untenable.

(2) Virus was produced in packets which sedimented with the mitochondria.

(3) Some virus-synthesizing organelle containing virus material sedimented with the mitochondria.

(4) Mitochondria, themselves, were the sites of synthesis of haemagglutinin and of assembly of RNA component and haemagglutinin into the mature virus particles.

It will be impossible to distinguish between the last three interpretations until techniques are available which yield guaranteed pure fractions and yet are sufficiently rapid to preserve virus activity. In the absence of such techniques, we must emphasize that the term mitochondrial fraction includes all cytoplasmic particles sedimented at $9000 \mathrm{~g}$. No evidence was obtained suggesting that the microsomal $(144,000 \mathrm{~g})$ fraction was in any way involved in the synthesis of EMC virus although 
virus was deposited with the microsomes from cells fractionated between 6 and $8 \mathrm{hr}$. after infection (Fig. 4). Microsomes and EMC virus have similar sedimentation properties; 70-80\% of the virus was recovered from the microsomal fraction when virus was added to an uninfected cell homogenate which was then fractionated (Table 1). Any virus free in the cell would be expected to deposit with the microsomes and therefore that found in the microsomal fraction obtained from 6 to $8 \mathrm{hr}$. infected cells was possibly mature virus recently liberated from the mitochondrial $(9000 \mathrm{~g})$ particles.

Sanders (1960) suggested that haemagglutinin synthesis and virus assembly are separate processes in EMC virus multiplication. Additional evidence for this view is that the ratio of haemagglutinin to plaque-forming titre was much higher in our mitochondrial fraction than in the microsomal fraction $8 \mathrm{hr}$. after infection. This suggests that the mitochondrial fraction contained haemagglutinin not yet incorporated into plaque-forming virus particles, although no difference was detected between the times of appearance of haemagglutinin and virus.

Biochemical changes induced in Krebs ascites tumour cells on infecting with EMC virus have been studied using ${ }^{14} \mathrm{C}$-labelled orotic acid and valine (Martin \& Work, 1961). Changes in the rate of incorporation of labels into cell materials after infection obscured incorporation into virus components and the movement of these components within the cell. However, the reported loss of phosphate soluble, nuclear RNA which was compensated by a similar rise in mitochondrial RNA possibly represented the transfer of infective RNA component from the nucleus to the mitochondrial fraction that we observed. Increased incorporation of orotic acid into cytoplasmic RNA during the appearance of virus was not due to viral RNA synthesis since this had already taken place (Martin \& Work, 1962).

Our results using biological markers suggest a hypothesis for the multiplication of EMC virus which has as its main features the replication of the RNA component in the nucleus of the cell during the eclipse phase and the transfer of this component to the cytoplasm where it may initiate and act as a template for the synthesis of haemagglutinin. The RNA component and haemagglutinin are then incorporated into infective particles. Similar conclusions have been reached by Martin \& Work (1961, 1962).

Franklin \& Rosner (1962) have studied by autoradiography the incorporation of $\left({ }^{3} \mathrm{H}\right)$ uridine into $\mathrm{L}$ cells infected by Mengo virus, which is closely related to EMC. They found decreased nuclear incorporation, followed by stimulated cytoplasmic incorporation during and after the appearance of virus, thus confirming the results obtained by Martin \& Work (1961). Franklin \& Rosner, unlike Martin \& Work, concluded that synthesis of virus RNA was cytoplasmic.

It has been amply demonstrated that RNA synthesis precedes the appearance of EMC virus in infected ascites cells (Sanders, 1960; Martin \& Work, 1962; this paper). Since in the $\mathrm{L}$ cells-mengo virus system virus was detected $2 \mathrm{hr}$. after infection, it may be presumed that only changes occurring in the first two hours have any relevance to viral RNA synthesis. During this time the stimulation of cytoplasmic incorporation as measured by autoradiographic techniques amounted to less than 2 photographic grains per cell (Franklin \& Rosner, 1962), whereas after virus multiplication was complete a stimulation of 50-60 grains per cell was observed. It seems that the experiment of Franklin \& Rosner has detected a gross disturbance of the 
nucleic acid metabolism of the host cells, but gives no indication of the site of viral RNA synthesis.

We are grateful to Dr F. K. Sanders, Dr E. M. Martin and Dr T. S. Work for advice and discussion during the course of this work. We wish to acknowledge the technical assistance of Miss J. Moss and Mr R. G. Harris.

\section{REFERENCES}

Aldridge, W. N. \&Johnson, M. K. (1959). Cholinesterase, succinic dehydrogenase, nucleic acids, esterase and glutathione reductase in sub-cellular fractions from rat brain. Biochem. J. 73, 270.

Bellett, A. J. D. (1960). Use of Pardee's $\mathrm{CO}_{2}$ buffer in plaque titration of EMC virus. Virology, 10, 285.

Bellett, A. S. D., Burness, A. T. H. \& Sanders, F. K. (1962). Infective ribo-nucleic acid component of cells infected by encephalomyocarditis virus. Nature, Lond. 195, 874.

Breitenfeid, P. M. \& Schäfer, W. (1957). The formation of fowl plague virus antigens in infected cells, as studied with fluorescent antibodies. Virology, 4, 328.

Burton, K. (1956). A study of the conditions and mechanism of the diphenylamine reaction for the colorimetric estimation of deoxyribonucleic acid. Biochem. J. 62, 315 .

Busch, H., Starbuck, W. C. \& Davis, J. R. (1959). A method for isolation of nuclei from cells of the Walker 256 carcinosarcoma. Cancer Res. 19, 684.

Frankin, R. M. \& Rosner, J. (1962). Localization of ribonucleic acid synthesis in mengovirus-infected L-cells. Biochim. biophys. Acta, 55, 240.

Gierer, A. \& Schramm, G. (1956). Infectivity of ribonucleic acid from Tobacco Mosaic Virus. Nature, Lond. 177, 702.

Huppert, J. \& Sanders, F. K. (1958). An infective 'ribonucleic acid' component from tumour cells infected with encephalomyocarditis virus. Nature, Lond. 182, 515.

Martin, E. M., Malec, J., Coote, J. L. \& Work, T. S. (1961). Studies on protein and nucleic acid metabolism in virus-infected mammalian cells. 3. Methods for the disruption of Krebs II mouse-ascites-tumour cells. Biochem. J. 80, 606.

Martin, E. M. \& Work, T. S. (1961). Studies on protein and nucleic acid metabolism in virus-infected mammalian cells. 4. The localization of metabolic changes within subcellular fractions of Krebs II mouse-ascites-tumour cells infected with encephalomyocarditis virus. Biochem. $J .81,514$.

Martin, E. M. \& Work, T. S. (1962). Studies on protein and nucleic acid metabolism in virus infected mammalian cells. 5. The Kinetics of synthesis of virus protein and virus ribonucleic acid in Krebs II mouse ascites tumour cells infected with encephalomyocarditis virus. Biochem. $J .83,574$.

Ogur, M. \& Rosen, G. (1950). The nucleic acids of plant tissues. 1. The extraction and estimation of desoxypentose nucleic acid and pentose nucleic acid. Arch. Biochem. 25, 262.

Reed, L. J. \& Muench, J. (1938). A simple method of estimating fifty per cent endpoints. Amer. J. Hyg. 27, 493.

SANDERs, F. K. (1960). Role of infective nucleic acid in the production of encephalomyocarditis virus. Nature, Lond. 185, 802.

Sanders, F. K., Huppert, J. \& Hoskins, J. M. (1958). Replication of an animal virus. Symp. Soc. exp. Biol. 12, 123. 